\title{
Paleocene of Menat Formation, France, reveals an extraordinary diversity of orthopterans and the last known survivor of a Mesozoic Elcanidae
}

Thomas Schubnel, Laure Desutter-Grandcolas, Romain Garrouste, Sophie Hervet, and Andre Nel Acta Palaeontologica Polonica 65 (2), 2020: 371-385 doi: http://dx.doi.org/10.4202/app.0676.2019

The orthopteran fauna of the Paleocene of Menat Formation (France) is revised. It comprises at least 12 species in the following clades: Grylloidea (an undescribed species, Menatgryllus longixiphus gen. et sp. nov.); Tettigoniidae (Prophasgonura lineatocollis); Elcanidae (Cenoelcanus menatensis gen. et sp. nov.); two Eumastacoidea (Paleochina duvergeri gen. et sp. nov. and Paleochina minuta sp. nov., tentatively placed in the extant family Chorotypidae). These two last taxa are compared to the other described fossil Eumastacoidea. As all these Eumastacoidea are represented by tegmina or hindwings, their previous attributions to the Eumastacidae sensu stricto are questionable. All previously described fossil Caelifera from Menat are considered of uncertain position. Those that were previously considered as Acridoidea are excluded from this clade. In consequence, the oldest described Acridoidea are Oligocene, at the time of diversification of the grasses on which these insects predominantly live, in accordance with the most recent molecular dating of the Acrididae. Cenoelcanus menatensis is the youngest and first Cenozoic representative of the Mesozoic Elcanidae, showing that this family survived the Cretaceous-Paleocene extinction and became extinct during the Paleogene.

Key words: Insecta, Ensifera, Elcanoidea, Acridoidea, Eumastacoidea, Paleogene, France.

Thomas Schubnel [thomas.schubnel@wanadoo.fr], Laure Desutter-Grandcolas [desutter@mnhn.fr ], Romain Garrouste [garrosut@mnhn.fr], and André Nel [anel@mnhn.fr] (corresponding author), Institut Systématique Evolution Biodiversité (ISYEB), Muséum national d'Histoire naturelle, CNRS, Sorbonne Université, Université des Antilles, EPHE, 57 rue Cuvier, CP 50, 75005 Paris, France. Sophie Hervet [sophie.hervet@yahoo.fr], Association Paléovergne, Musée de Paléontologie de Menat, Place de la Mairie, F-63560 Menat, France.

This is an open-access article distributed under the terms of the Creative Commons Attribution License (for details please see creativecommons.org), which permits unrestricted use, 
distribution, and reproduction in any medium, provided the original author and source are credited.

For Full text $(2,143.3 \mathrm{kB})$ 